\title{
窒化物半導体異種接合の界面評価と制御
}

\author{
橋詰 保・谷田部然治・佐藤威友 \\ 北海道大学 量子集積エレクトロニクス研究センター \\ 齿 060-0814 北海道札幌市北区北 13 条西 8 丁目 \\ （2013 年 10 月 4 日受付；2013 年 10 月 29 日掲載決定)
}

\section{Interface Characterization and Control of GaN-based Heterostructures}

Tamotsu Hashizume, Zenji Yatabe and Taketomo Sato

Research Center for Integrated Quantum Electronics, Hokkaido University,

Nishi-8, Kita-13, Kita-ku, Sapporo, Hokkaido 060-0814

(Received October 4, 2013 ; Accepted October 29, 2013)

\begin{abstract}
Interface properties of GaN-based heterostructures have been characterized. Schottky contacts on dry-etched n-GaN layers showed leaky I-V characteristics. An anneal process at $400^{\circ} \mathrm{C}$ was effective in recovering the rectifying characteristics. To characterize interface properties of $\mathrm{Al}_{2} \mathrm{O}_{3}$ insulated gates on $\mathrm{AlGaN} / \mathrm{GaN}$ structures with and without the inductively coupled plasma (ICP) etching of $\mathrm{AlGaN}$, we have developed a $\mathrm{C}-\mathrm{V}$ calculation method taking into account electronic state charges at the $\mathrm{Al}_{2} \mathrm{O}_{3} / \mathrm{AlGaN}$ interface and a photoassisted $\mathrm{C}-\mathrm{V}$ technique utilizing photons with energies less than the bandgap of AlGaN. It was found that the ICP etching caused the monolayer-level interface roughness, disorder of the chemical bonds and formation of various types of defect complexes at the AlGaN surface, resulting in poor $\mathrm{C}-\mathrm{V}$ characteristics due to high-density interface states at the $\mathrm{Al}_{2} \mathrm{O}_{3} / \mathrm{AlGaN}$ interface.
\end{abstract}

KEYWORDS : GaN, heterostructure, interface state, ICP, C-V

\section{1.は じめ に}

トランジスタの動作時のオン抵抗 $\left(R_{o n}\right)$ は, 以下の 近似式で比較できる。

$$
R_{o n}=\frac{V_{B}^{2}}{\varepsilon \mu E_{\max }^{3}}
$$

ここで, $V_{B}$ は動作電圧, $\varepsilon$ と $\mu$ は誘電率と移動度, $E_{\max }$ は絶縁破壊電界である。窒化ガリウム $(\mathrm{GaN})$ や炭化ケ イ素 $(\mathrm{SiC})$ は, $\mathrm{Si}$ と比較して約 10 倍の絶縁破壊電界 $E_{\max }$ を有するため, オン抵抗を $\mathrm{Si}$ 素子より 2 ケ夕以上 低減でき, ジュール損失を著しく抑制することができ る。このため, $\mathrm{GaN}$ と $\mathrm{SiC}$ は超低損失パワー素子用材 料として期待され, 雨者は同等の材料ポテンシャルを持 っている ${ }^{1,2)}$ 。

$\mathrm{GaN}$ 系材料の特長は, 異種（へテロ）接合を巧みに 利用できる点にある。Fig. 1 に示すように, ヘテロ接合

E-mail : hashi@rciqe.hokudai.ac.jp
界面に高密度・高移動度の 2 次元電子層（2DEG）を形 成することができ，単純な構造の横型素子（高電子移動 度トランジスタ：HEMT）において非常に低いオン抵抗 を実現している ${ }^{2)}$ 。さらに最近では，大口径 Si 基板上へ の結晶成長が可能となり, GaN 結晶基板が研究途上で あるという点やコスト面での欠点をカバーし, GaN-on$\mathrm{Si}$ 素子は実用化への開発が猛烈な勢いで進展してい る ${ }^{3)}$ 。

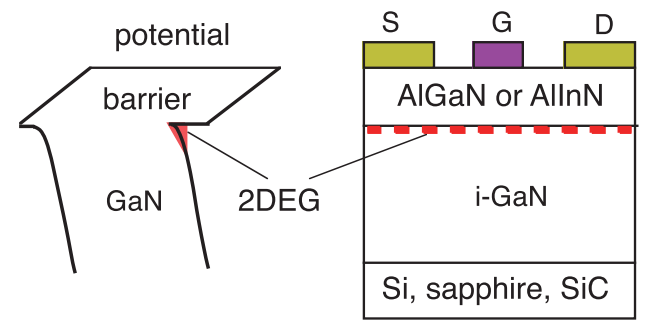

Fig. 1. (color online). GaN-based heterostructure including two-dimensional electron gas (2DEG). 


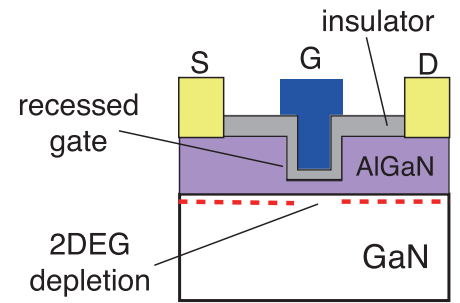

Fig. 2. (color online). Recessed gate $\mathrm{AlGaN} / \mathrm{GaN}$ HEMT structure.

電力変換器 (インバータ) 応用に関しては, 故障時の 負荷保全の観点から，スイッチング用トランジスタにノ ーマリオフ動作（ゲート入力なしの場合にオフ状態）が 要求される。Fig. 2 に, GaN 系素子で一般的に用いられ る $\mathrm{AlGaN} / \mathrm{GaN}$ トランジスタを示すが，ノーマリオフ動 作を実現するために「リセスゲート構造」を採用する例 が多く，ドライエッチングによりゲート部のみに溝構造 を形成し，直下の $2 \mathrm{DEG}$ を空乏化させる。このため, ドライエッチングが表面特性および接合特性に与える影 響を詳細に評価する必要がある。

また, 絶縁膜利用は, ゲート構造および表面安定化構 造に欠かせない。特に, ノーマリオフ素子における順バ イアス印加時の障壁を形成する上で, 絶縁ゲート構造は 重要である。また, 高温環境での動作が $\mathrm{GaN}$ トランジ ス夕に期待されているため, ゲート接合部の化学的安定 性の点から, 金属ゲートと比較して絶縁ゲート構造は格 段に優れている。さらに, アクセス領域の表面準位の低 減や表面安定化にとっても, 絶縁膜利用は不可欠であ る4)。

そこで本稿では，ドライエッチングされた表面の特性 および絶縁膜/ $\mathrm{AlGaN}$ の界面特性の評価の例を報告す る。

\section{2. ドライエッチング面に形成した GaN ショ ットキー接合の評価}

Fig. 3 に試料構造を示す。低転位密度自立基板上に MOCVD 法でn-GaN を成長した試料を用いた。n-GaN 層の $\mathrm{Si}$ ドーピング密度は $5 \times 10^{16} \mathrm{~cm}^{-3}$ である。誘導結 合プラズマ（ICP）を利用して GaN 表面を $50 \mathrm{~nm}$ エッチ ングした。ICP プラズマ支援プロセスでは, $\mathrm{Cl}_{2} / \mathrm{BCl}_{3}$ 混 合ガスを用い, $\mu$ 波電力 $300 \mathrm{~W}$, バイアス電力 $5 \mathrm{~W}$ とし た。エッチングレートは約 $10 \mathrm{~nm} / \mathrm{min}$ である。後処理 として, 室温にてオゾン UV アッシングを行った。エッ チング面に Ni ショットキー接合を形成した。ICP エッ チングを行っていないショットキー接合を標準試料とし た。

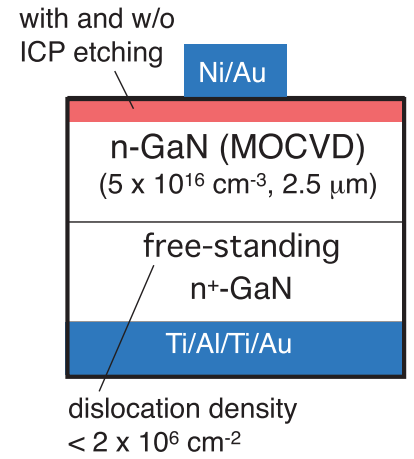

Fig. 3. (color online). Schottky diode structure using n-GaN layer grown on a free-standing GaN substrate.

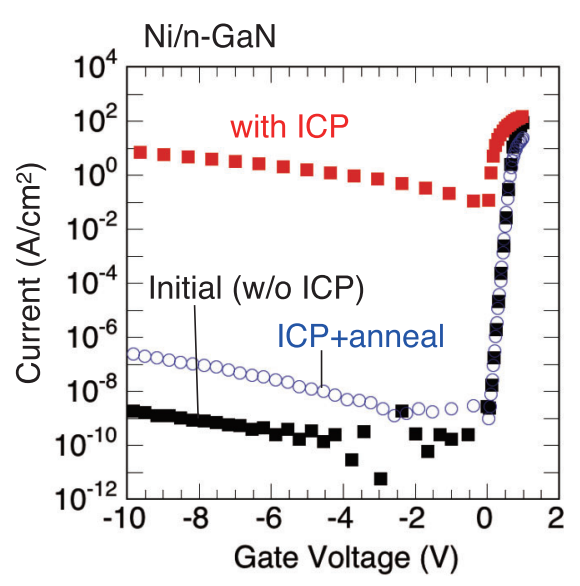

Fig. 4. (color online). I-V characteristics of n-GaN Schottky diodes.

Fig. 4 に室温の I-V 特性を示す。ICP エッチングなし の標準試料は良好な特性を示し, 理想因子は 1.08 , 障壁 高は $1.0 \mathrm{eV}$ であった。また, 低い逆方向漏れ電流が観 測され, その温度およびバイアス依存性は, 熱励起電界 放出モデルによる計算と良く一致した。一方, ICP エッ チングを行った接合は, 非常にリーキーな特性を示し た。ICP プロセスにより, 高密度の欠陥が $\mathrm{GaN}$ 表面に 生成され, 障壁高の低下を含むポテンシャル変化によ り，トンネル輸送成分が大幅に増加したと思われる ${ }^{5 \sim 7) 。 ~}$ $\mathrm{N}_{2}$ 雲囲気中, $400^{\circ} \mathrm{C}$ の熱処理を行うと, I-V 特性の回 復が観測された。しかし, 逆方向漏れ電流のバイアス依 存性は標準試料より強く, かつ, 温度依存性は熱励起電 界放出モデルに従わない結果となった。これらは, ICP プロセスにより誘起された $\mathrm{GaN}$ 表面欠陥が, 熱処理に より完全に回復していないことを示している。 


\section{ICP エッチングした AlGaN 表面を含む $\mathrm{Al}_{2} \mathrm{O}_{3} / \mathrm{AlGaN} / \mathrm{GaN}$ 構造の容量-電圧特性}

\section{1 基本 $\mathrm{C}-\mathrm{V}$ 特性}

Fig. 5 に, $\mathrm{Al}_{2} \mathrm{O}_{3} / \mathrm{AlGaN} / \mathrm{GaN}$ 構造の模式図を示す。 $\mathrm{ICP}$ を利用して $\mathrm{AlGaN}$ 表面をエッチングした試料とエ ッチングしない試料を準備した。ICP プラズマ支援プロ セスの条件は, 上述の $\mathrm{GaN}$ の場合と同様である。アル ミナ膜は原子層堆積（ALD）法により形成し, 膜厚は $20 \mathrm{~nm}$ とした。まず，断面 TEM 像の観察を行った。ICP エッチング前は $\mathrm{AlGaN}$ 膜厚は $34 \mathrm{~nm}$ であり, エッチン グ後は $27 \mathrm{~nm}$ であったため, エッチング深さは $7 \mathrm{~nm}$ と 求められた。また，エッチング後の界面は比較的良好な 平坦性を示したが，1 原子層程度のステップが多数観測 された。

Fig. 6 に C-V 測定結果を示す。二つの試料とも 2-step の曲線を示し，これは HEMT-MOS 構造に特有の特性で

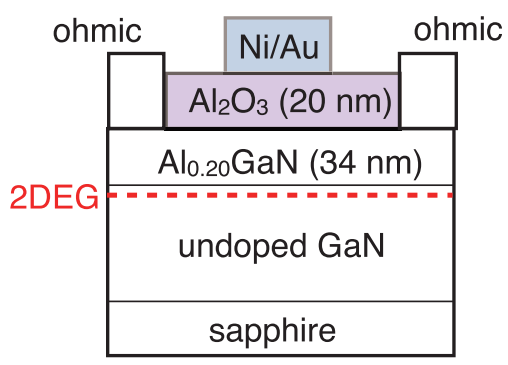

Fig. 5. (color online). $\mathrm{Al}_{2} \mathrm{O}_{3} / \mathrm{AlGaN} / \mathrm{GaN}$ structure with and without ICP-etching of AlGaN surface.

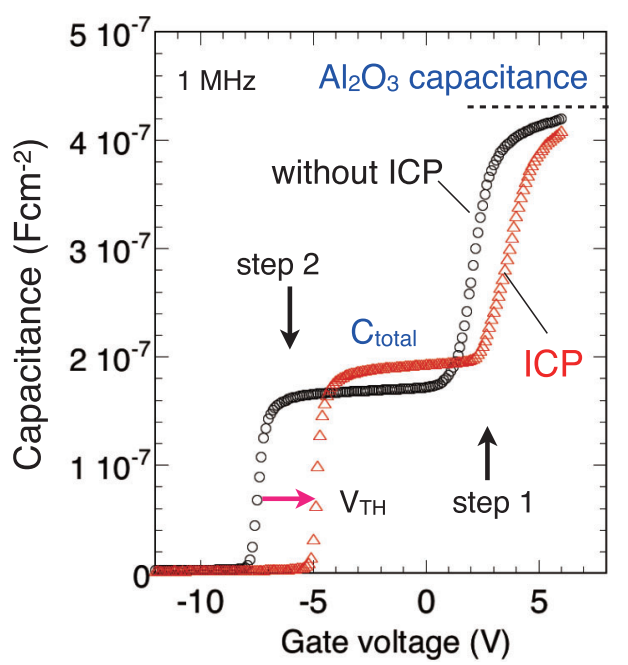

Fig. 6. (color online). C-V characteristics of $\mathrm{Al}_{2} \mathrm{O}_{3} / \mathrm{AlGaN} /$ $\mathrm{GaN}$ structures with and without the ICP etching of AlGaN surface.
ある ${ }^{8 \sim 10)}$ 。エッチング試料では, $\mathrm{Al}_{2} \mathrm{O}_{3}$ 層容量と $\mathrm{AlGaN}$ 障壁層容量の合成容量 $\left(\mathrm{C}_{\text {total }}\right)$ が増加し, 増加量は $\mathrm{AlGaN}$ 層のエッチング深さ $7 \mathrm{~nm}$ に正確に一致した。ま た, $2 \mathrm{DEG}$ 空そのしきい值 $\left(\mathrm{V}_{\mathrm{TH}}\right)$ は浅くなり，これも $\mathrm{AlGaN}$ 障壁層が薄くなったことと一致する。エッチン グ後も二つのステップは観測され， $\mathrm{AlGaN}$ 表面のポテ ンシャル制御は著しく乱されてはいない。

この C-V 特性を理解するために, 数值計算を行った。 計算には，分極電荷と $\mathrm{Al}_{2} \mathrm{O}_{3} / \mathrm{AlGaN}$ 界面の電子捕獲準 位を仮定した。また，Shockley-Read-Hall（SRH）統計 に基づいた界面準位からの電子放出時定数を考慮し, C$\mathrm{V}$ 測定の掃印時間内に応答する準位のみを電荷変化に取 り入れた ${ }^{8,11)}$ 。Fig. 7 に計算結果の一例を示す。実線は $\mathrm{Al}_{2} \mathrm{O}_{3} / \mathrm{AlGaN}$ 界面に電位準位を仮定しない場合の理想 $\mathrm{C}-\mathrm{V}$ 曲線である。順バイアス側と逆バイアス側のポテン シャル分布を Fig. 8 に示す。順バイアス領域の一定容量 は $\mathrm{Al}_{2} \mathrm{O}_{3}$ の絶縁膜容量に相当する。また, 0 〜 $-8 \mathrm{~V}$ の 一定容量は, $\mathrm{Al}_{2} \mathrm{O}_{3}$ 膜と $\mathrm{AlGaN}$ 膜の合成容量に対応し ている。

次に, Fig. 7 の挿入図に示す分布を仮定して，界面準 位の影響を調べた。界面準位の影響は主として C-V 特 性の順バイアス領域に出現する。Fig. 8 (a) に示すよう に，この領域では $E_{F}$ は $\mathrm{AlGaN}$ の禁制帯内に位置するた め, バイアス変化により界面準位の占有確率は変化す る。また， $E_{F}$ 近傍の界面準位は伝導帯下端より比較的 浅いエネルギーを持つため, $E_{F}$ 以上の準位からの電子 放出時定数は小さい。したがって, 通常の MOS 構造の 特性と同様に，界面準位のイオン化による過剩電荷が $\mathrm{C}-\mathrm{V}$ 曲線の傾きを減少させ，その度合いは準位密度に依 存する。界面準位密度がきわめて高い場合, 順バイアス

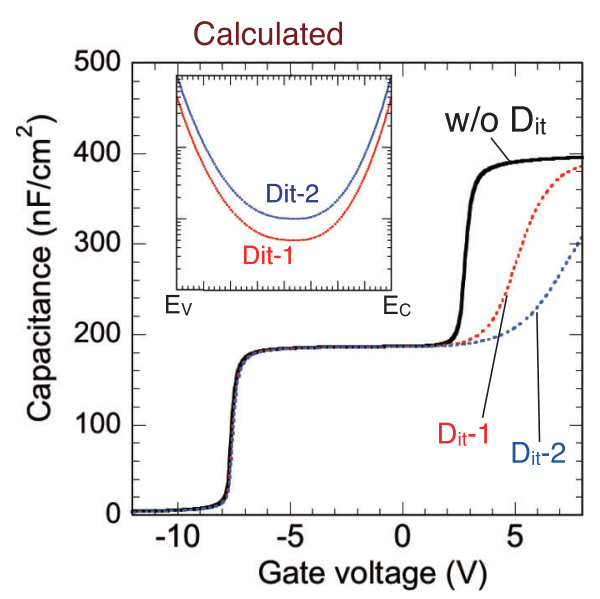

Fig. 7. (color online). Calculated $\mathrm{C}-\mathrm{V}$ curves of $\mathrm{Al}_{2} \mathrm{O}_{3} /$ $\mathrm{AlGaN} / \mathrm{GaN}$ structure. 


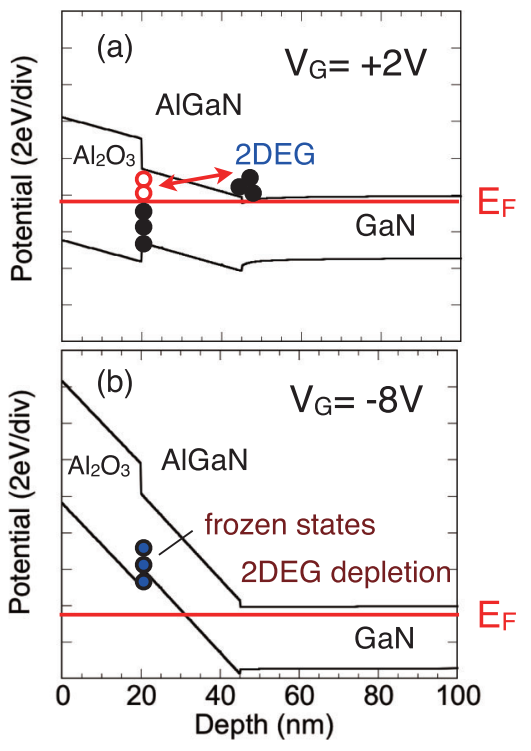

Fig. 8. (color online). Band diagram of $\mathrm{Al}_{2} \mathrm{O}_{3} / \mathrm{AlGaN} / \mathrm{GaN}$ structure at (a) $\mathrm{V}_{\mathrm{G}}=+2 \mathrm{~V}$ and (b) $\mathrm{V}_{\mathrm{G}}=-8 \mathrm{~V}$.

領域での容量増加は観測されず，一定容量 $\left(C_{\text {total }}\right)$ が広 い領域で続くことになる。

一方，しきい值電圧近傍のバイアスでは, Fig. 8（b) に示すように， $E_{F}$ が $\mathrm{AlGaN}$ の価電子带上端よりはるか に低いエネルギー位置にあるため, 界面準位の占有確率 がバイアスに依存しない。このため, このバイアス領域 では，イオン化した界面準位は固定電荷のごとくふるま い，主としてしきい值電圧シフトにその影響が現れる。 これは, 通常の MOS 構造の C-V 特性と大きく異なる点 である。さらに, $\mathrm{Al}_{2} \mathrm{O}_{3} / \mathrm{AlGaN}$ 界面の電子準位の大部 分は, 伝導带への電子放出時定数が室温で非常に大きく なるため, しきい值電圧シフトは見かけ上小さくなり, イオン化した界面準位電荷を正確に求めることが難しい (室温でも界面準位は凍結状態)。特にゲート電圧掃印が 負バイアス領域に限られている場合, 界面準位への電子 捕獲が十分ではなく, 見かけ上のしきい值電圧シフトは 非常に小さくなる。このような場合, 界面準位密度を過 小評価する例が多く, 結果の引用には注意を要する。

3.2 フィッティングと光支援 C-V 法による界面準位 密度分布の推定

以上の解釈を基盤として, fitting による界面準位密度 の算出を行った。Fig.9（a）に, ICP エッチングを行っ た試料の実験值と計算值の比較を示す。 $\mathrm{Al}_{2} \mathrm{O}_{3} / \mathrm{AlGaN}$ 界面に電子捕獲準位を仮定しない場合, 理想 C-V 曲線 は二つのステップとも急峻な変化を示す。しかし, 実験 值では, 順バイアスにおいて, C-V 曲線の傾きは緩く, かつ, 容量の立ち上がり電圧が正バイアス方向にシフト
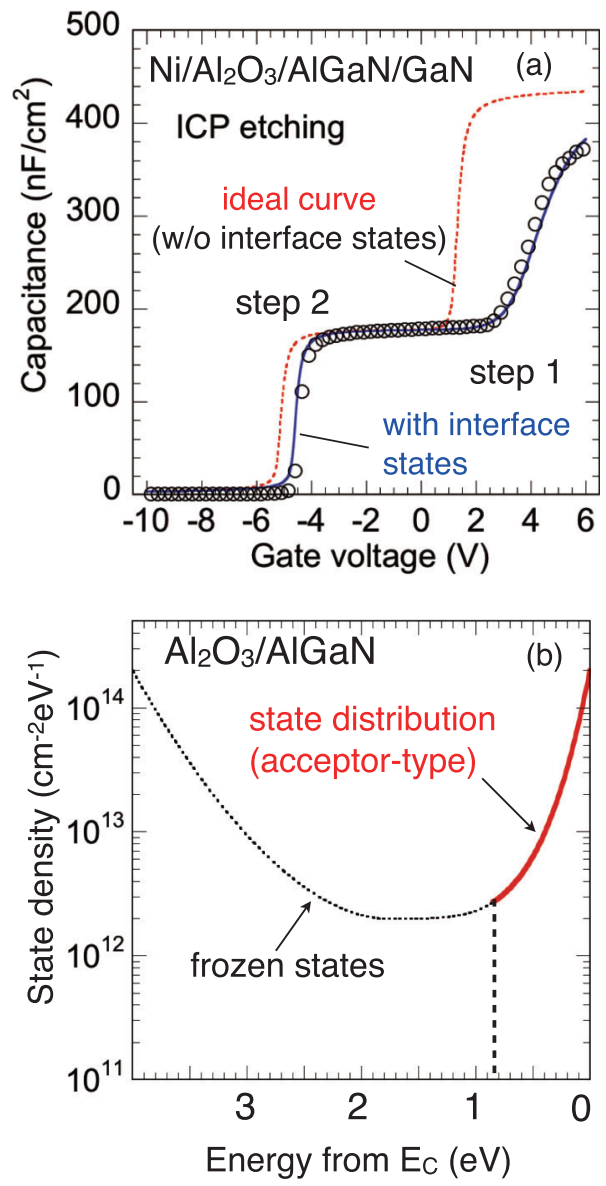

Fig. 9. (color online). (a) Comparison between the calculated and experimental $\mathrm{C}-\mathrm{V}$ cuves of $\mathrm{Al}_{2} \mathrm{O}_{3} / \mathrm{AlGaN} / \mathrm{GaN}$ structures with the ICP etching process. (b) Interface state density distribution used in the calculation.

していることがわかる。そこで, 界面準位を仮定した計 算により $\mathrm{C}-\mathrm{V}$ 曲線の傾きと立ち上がり電圧の変化を再 現することができた。この fitting 結果をもとに, 界面準 位密度分布の推定を行った。Fig.9（b）に推定された密 度分布を示す。SRH 統計による, 界面準位からの電子 放出時定数は次式で与えられる。

$$
\tau=\frac{1}{\sigma_{t h} v_{t h} N_{C}} \exp \left(\frac{E_{T}}{k T}\right)
$$

ここで， $\sigma_{t h}$ は捕獲断面積であり，計算では $1 \times 10^{-16}$ $\mathrm{cm}^{2}$ を採用した。 $V_{t h}$ はキャリア熱速度, $N_{C}$ は伝導帯有 効状態密度, $E_{T}$ は伝導带下端からの準位のエネルギー である。Fig. 9（b）の太い実線で示す電子準位が, C-V 測定に応答していると判断できる。一方, 破線で示され た分布は，ゲート電圧掃印により，たとえ電子占有関数 が0になったとしても，きわめて大きな放出時定数のた めに, 電子を捕獲した状態を保持し,「凍結準位」とし て振る舞うため, C-V 結果に顕著な影響を与えない。こ 

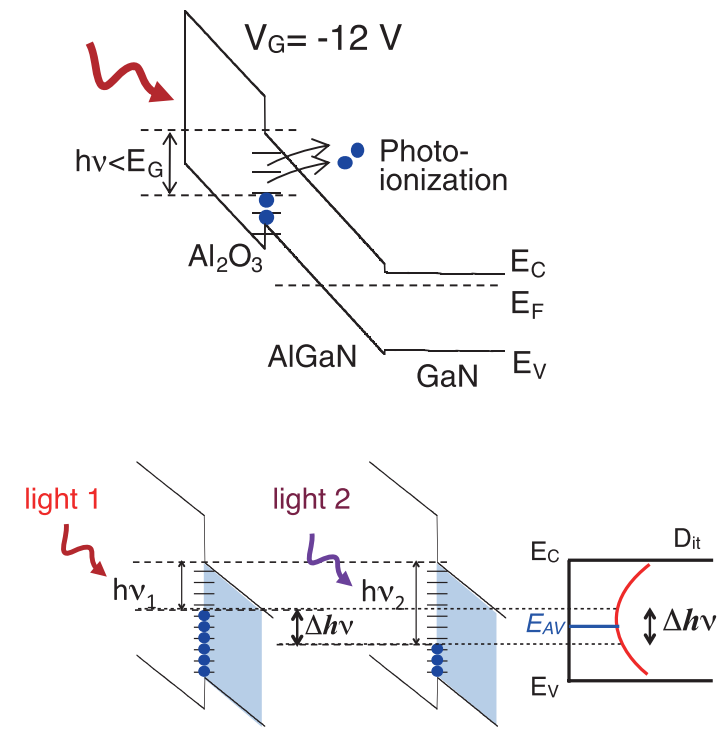

Fig. 10. (color online). Schematic illustration of photoassited C-V method.

のように, 室温 $\mathrm{C}-\mathrm{V}$ 測定から得られる界面準位の情報 は, $\mathrm{AlGaN}$ の禁制帯幅の $1 / 4$ 程度に限定され, 禁制帯 中央より深い電子準位の検出は難しい。

この問題を解決するために, 光支援 $\mathrm{C}-\mathrm{V}$ 法を開発し た ${ }^{8)}$ 。原理図を Fig. 10 に示す。暗状態で順バイアス印 加により, バンドをほぼフラット状態にする（酸化膜容 量が目安)。ここで, 界面準位のほぼすべてが電子を捕 獲した状態である。次に暗状態のまま逆バイアスに掃印 し, 2 DEG 空乏（容量值はほほ０）のバイアスで, Al$\mathrm{GaN}$ の禁制帯幅以下のエネルギーを持つ単色光を照射 する。Fig. 10 の上図に示すように, 単色光エネルギー に対応した界面準位から電子放出が生じ, 界面電荷変化 をもたらす。次に, 単色光を off し, 暗状態で正バイア ス方向に C-V 測定を再開すると, 界面電荷変化量に対 応した $\mathrm{C}-\mathrm{V}$ 曲線の並行シフトが観測される（負バイア ス方向)。Fig. 10 の下図に示すように, 単色光のエネル ギーを変化させて, 光支援 $\mathrm{C}-\mathrm{V}$ 測定を行うと, $\mathrm{C}-\mathrm{V}$ シ フト電圧は単色光のエネルギーに対応して大きくなる。

Fig. 11 に測定結果の 1 例を示す。AlGaN の禁制帯幅 以下のエネルギーを持つ単色光の照射により, C-V 曲線 がほぼ完全な平行シフトを示している。これは, Fig. 8 に示したように，禁制帯中央より深い準位が「凍結状 態」にあることを証明した結果である。光照射による電 圧シフト量から, 次の簡単な式を使って, 準位密度を算 出できる。

$$
D_{\text {it }}\left(E=E_{\mathrm{AV}}\right)=\frac{C_{\text {TOTAL }} \cdot \Delta V_{2}}{q \cdot \Delta h \nu}
$$

ここで, $C_{\text {TOTAL }}$ は $\mathrm{Al}_{2} \mathrm{O}_{3}$ 層と $\mathrm{AlGaN}$ 層の直列合成容量

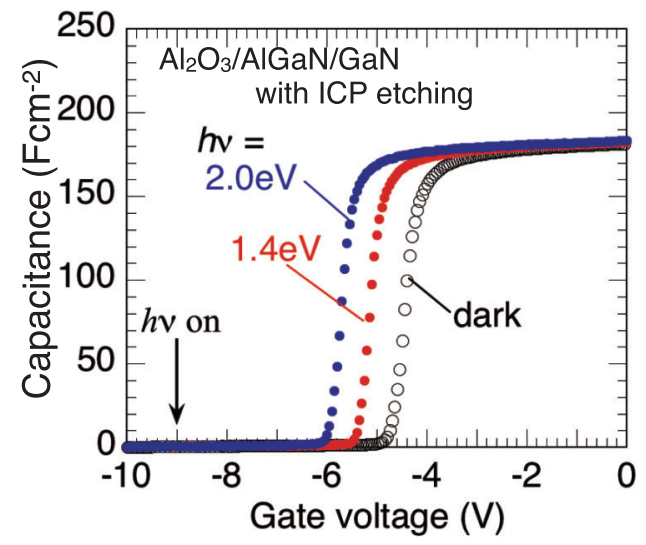

Fig. 11. (color online). Photoassited $\mathrm{C}-\mathrm{V}$ characteristics of $\mathrm{Al}_{2} \mathrm{O}_{3} / \mathrm{AlGaN} / \mathrm{GaN}$ structure with the ICP etching.

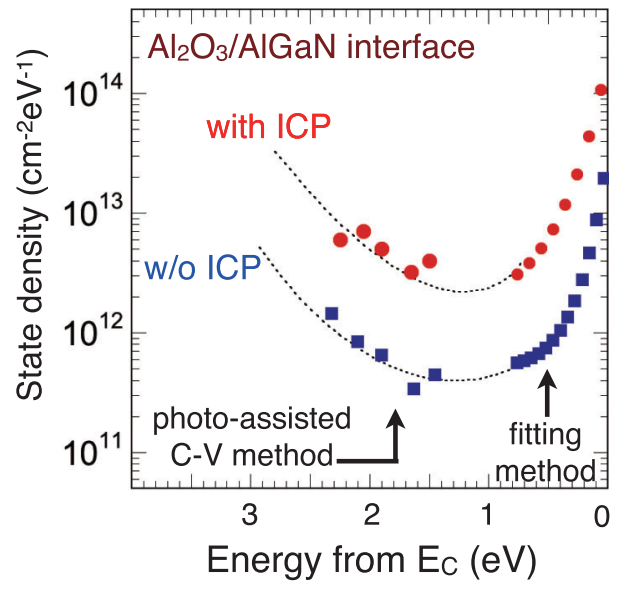

Fig. 12. (color online). State density distributions at the $\mathrm{Al}_{2} \mathrm{O}_{3} / \mathrm{AlGaN}$ interface determined by the photoassisted $\mathrm{C}-\mathrm{V}$ and the fitting analysis.

であり, $\Delta V_{2}$ は電压シフト量, $\Delta h \nu$ は二つの単色光のエ ネルギー差である。

Fig. 12 に光支援 C-V 法と fitting 法により算出した, $\mathrm{Al}_{2} \mathrm{O}_{3} / \mathrm{AlGaN}$ 界面の電子準位密度分布を示す。HEMTMOS 構造を用いて算出した初めての例である。禁制帯 中央付近に最小值を持つU 字分布を示した。ICPエッ チングを行っていない試料では, 準位密度の最小值は $10^{12} \mathrm{~cm}^{-2} \mathrm{eV}^{-1}$ を下回る值となったが，注意深く形成し た $\mathrm{Al}_{2} \mathrm{O}_{3} / \mathrm{GaN}$ 界面の場合より数倍高い值である ${ }^{12)}$ 。界 面準位密度は下地結晶が含む欠陥密度に関連している可 能性がある。

一方, ICP エッチングされた $\mathrm{AlGaN}$ 面に形成した試 料では, 界面準位密度が約 1 ケ夕増加している。Fig. 13 に $\mathrm{Al}_{2} \mathrm{O}_{3} / \mathrm{AlGaN}$ 界面の断面 TEM 像を示すが, ICP エッ チング後の $\mathrm{AlGaN}$ 表面には原子層オーダーのステップ 

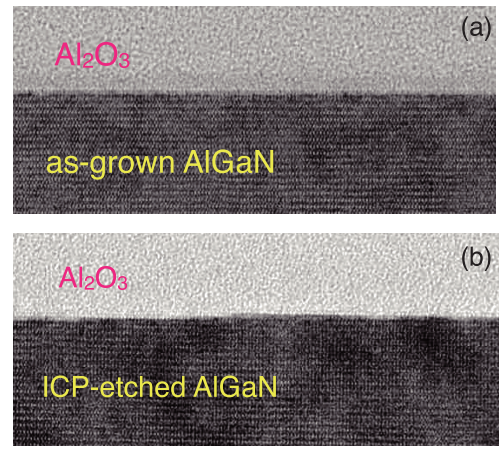

$10 \mathrm{~nm}$

Fig. 13. (color online). TEM images of $\mathrm{Al}_{2} \mathrm{O}_{3} / \mathrm{AlGaN}$ interfaces (a) with and (b) without the ICP etching of the AlGaN surface.

が多数観測された。これより, 格子結合の乱れが発生 し，ステップエッジを中心に高密度のダングリングボン ドが存在すると思われ，エネルギー的に連続分布を持つ 界面準位密度が増加したと考えられる。また，主たるエ ッチング反応は, 塩素ラジカルとの反応による $\mathrm{Ga}$ およ び $\mathrm{Al}$ 塩化物の生成とその気相中への離脱である。しか し, 副反応として, $\mathrm{NCl}_{3}$ 等の生成の可能性もあり, ま た塩化物の蒸気圧が低いことから, $\mathrm{AlGaN}$ 表面で窒素 空乏が生じている可能性がある。このため, ICP エッチ ング後の $\mathrm{AlGaN}$ 表面は窒素空孔に関連した表面欠陥を 含んでいる可能性があり，これも界面準位増加の要因の 一つと考えられる。実際, Fang らは ${ }^{13)}$, ICP エッチング した $\mathrm{n}-\mathrm{GaN}$ 表面にショットキー接合を形成し, DLTS 法 により窒素空孔に関連する梁い準位を検出している。

\section{4. と め}

ドライエッチングされた $\mathrm{GaN}$ 㧍よび $\mathrm{AlGaN}$ 表面の特 性を評価した。ICP エッチングを行った n-GaN 表面に 形成したショットキー接合は, オーミック特性に近い非 常にリーキーな特性を示した。高密度の欠陥が GaN 表 面に生成され，障壁高の低下を含むポテンシャル変化に
よりトンネル輸送成分が大幅に増加したと思われる。 $400^{\circ} \mathrm{C}$ の熱処理により I-V 特性は改善したが, 表面に導 入された欠陥は完全には回復しない。次に, $\mathrm{AlGaN} /$ $\mathrm{GaN}$ へテロ接合に $\mathrm{Al}_{2} \mathrm{O}_{3}$ 絶縁ゲートを形成し, $\mathrm{Al}_{2} \mathrm{O}_{3} /$ $\mathrm{AlGaN}$ 界面の電子準位密度分布を推定した。界面準位 からの電子放出時定数を考虑する数值計算により, 実験 的 C-V 曲線を説明することができた。さらに, fitting 法 と光支援 $\mathrm{C}-\mathrm{V}$ 法により界面準位密度分布を算出し, ICP エッチングされた $\mathrm{AlGaN}$ 面に形成した試料では，エッ チングを行わない場合と比較して, 界面準位密度が約 1 ケ夕程度増加することが明らかになった。 $\mathrm{AlGaN}$ 表面 における原子層レベルのステップ，化学結合の乱れ，お よび表面結晶欠陥が, $\mathrm{Al}_{2} \mathrm{O}_{3} / \mathrm{AlGaN}$ 界面の高密度電子 準位の生成に関与していると思われる。

\section{文献}

1) 木本恒暢 : 応用物理 80,673 (2011).

2) 葛原正明 : 応用物理 81, 464 (2012).

3) "Special Issue on GaN Electronic Devices" : IEEE Trans. Electron Dev. 60, no. 10, (2013).

4) 橋詰 保: 応用物理 81, 479 (2012).

5) T. Hashizume and H. Hasegawa : Appl. Surf. Sci. 234, 387 (2004).

6) T. Hashizume, S. Ootomo and H. Hasegawa : Appl. Phys. Lett. 83, 2952 (2003).

7) C. Lee, H. Sekiguchi, H. Okada and A. Wakahara : Jpn. J. Appl. Phys. 51, 076503 (2012).

8) C. Mizue, Y. Hori, M. Miczek and T. Hashizume : Jpn. J. Appl. Phys. 50, 021001 (2011).

9) M. Tapajna and J. Kuzmik: Appl. Phys. Lett. 100, 113509 (2012).

10) S. Huang, Q. Jiang, S. Yang, Z. Tang and K.J. Chen : IEEE Electron Dev. Lett. 34, 193 (2013).

11) M. Miczek, C. Mizue, T. Hashizume and B. Adamowicz: J. Appl. Phys. 103, 104510 (2008).

12) Y. Hori, C. Mizue and T. Hashizume : Jpn. J. Appl. Phys. 49, 080201 (2010).

13) Z.-Q. Fang, D.C. Look, X. -L. Wang, J. Han, F.A. Khan and I. Adesida : Appl. Phys. Lett. 82, 1562 (2003). 